\section{ANALYSIS OF ATHLETIC INJURIES, BIOMECHANICAL ASPECTS AND SPORTS PERFORMANCE IN AMPUTEE SOCCER - A SYSTEMATIC REVIEW}

${ }^{1}$ Aneta Kasprzyk, ${ }^{2}$ Kasinska Zofia, ${ }^{3}$ Narloch Dominika, ${ }^{4,5}$ Grygorowicz Monika. ${ }^{1}$ FitandFuture, St. Clement, Jersey (UK); ${ }^{2}$ Department of Adapted Physical Activity, Poznan University of Physical Education, Poznan, Poland; ${ }^{3}$ Department of Physiotherapy in Dysfunctions of the Locomotor System and Sports Medicine, The Jerzy Kukuczka Academy of Physical Education, Katowice, Poland; ${ }^{4}$ Department of Physiotherapy, Poznan University of Medical Sciences, Poznan, Poland; ${ }^{5}$ Rehasport Clinic FIFA Medical Centre of Excellence, Poznan, Poland

\subsection{6/bjsports-2021-IOC.386}

Background Many studies show the beneficial effects of sport activity on amputees. Understanding of biomechanical factors, performance and injury epidemiology in amputee soccer (AS) can contribute to implement injury prevention measures and develop suitable training programs to reduce number of injuries, increase sport performance, and ultimately improve quality of life in this population.

Objective To analyse incidence and/or prevalence of sports injuries in AS, to determine the impact of amputation on sports performance in AS, to examine biomechanics aspects of AS.

Design We searched PubMed, MEDLINE, SPORTDiscus, Scopus, Web of Science, Journals@Ovid, Academic Search Ebsco using keywords (amput*, prosthe*, disarticulation, hemipelvectomy, crutch) AND (futbol, soccer, football*, athlete*).

Setting Any amputee soccer competition level.

Participants Amputee soccer players.

Interventions Any paper tackling the issue of the incidence, type, pattern of injury and/or describing biomechanical factors and/or sport performance in AS. Joanna Briggs Institute tools were used to assess the quality of studies.

Main Outcome Measurements Injury, biomechanics- and performance-specific outcomes.

Results From 375 articles, 26 studies were included related to injury $(n=1)$, biomechanics $(n=3)$, and performance $(n=22)$ in AS. Majority of studies had a descriptive or analytical cross-sectional design. The results showed that AS is a sport with a low risk of injury and usage of Loftstrand crutches by players increase symmetrical gait pattern with better scapular resting position, than in other amputee wheelchair sports. None of the studies has met all criteria relevant to JBI tool.

Conclusions Analysis of the studies revealed that there is a base of knowledge on AS injuries, biomechanics, and athletic performance. However, limitations, in terms of methodological deficits, small sample size, and in some cases, laboratory setting, are reasons for future research to place greater importance on reducing the risk of bias to increase the reliability and validity of study results.

\section{PREVALENCE AND BURDEN OF HEALTH PROBLEMS IN TOP-LEVEL FOOTBALL REFEREES}

\footnotetext{
${ }^{1,2}$ Christian Moen, ${ }^{1,4}$ Thor Einar Andersen, ${ }^{1,3}$ Ben Clarsen, ${ }^{4}$ Gitte Madsen-Kaarød, 1,2Torstein Dalen-Lorentsen. 'Oslo Sports Trauma Research Centre, Oslo, Norway; ${ }^{2}$ Norwegian School of Sports Sciences, Oslo, Norway; ${ }^{3}$ Department of Health Promotion, Norwegian Institute of Public Health, Bergen, Norway; ${ }^{4}$ The Norwegian FA Sports Medicine Clinic, Oslo, Norway
}

10.1136/bjsports-2021-IOC.387
Background Top-level football referees make decisions during strenuous physical activity and often under great mental pressure. Despite their central role in a football match, little is known about referees' health problems, particularly female referees.

Objective To investigate the prevalence and burden of health problems in female and male top-level football referees.

Design Prospective cohort study.

Setting Female and male referees from the Norwegian female and male top divisions.

Patients (or Participants) All top-level referees $(n=55)$ were included in this study.

Interventions (or Assessment of Risk Factors) Referees reported health problems (injuries and illnesses) through text messages for 49 weeks using the Oslo Sports Trauma Research Center Questionnaire on Health Problems (OSTRC-H2).

Main Outcome Measurements Prevalence of all health problems.

Results On average, 34\% (95\% CI 31-36\%) of referees reported at least one health problem each week, and $20 \%$ (95\% CI 19-22\%) reported substantial health problems. The compliance was $98.1 \%$. The injury incidence was 3 injuries per athlete-year (95\% CI 2.5 to 3.5) and 12 injuries per 1000 match hours (95\% CI 7 to 19). Gradual-onset injuries were most prevalent, with an average weekly prevalence of $23 \%$, and caused the greatest absence from training and matches (60\% of total time loss). Of the 156 reported injuries, $36 \%$ were related to the lower-leg and foot. Illnesses represented a small portion of the overall burden of health problems. Female referees reported more health problems than male referees, and on-field referees reported more health problems than assistant referees.

Conclusions Top- level referees reported a high prevalence of health problems during one full season. Gradual onset injuries to the lower-leg and foot represented the highest injury burden, especially in female referees.

\section{PERFORMANCE HEALTH MANAGEMENT IN ENGLISH PROFESSIONAL FOOTBALL}

Kunle Odetoyinbo, McKay Carly. ESPARC Ltd/University of Bath, Bath, UK

\subsection{6/bjsports-2021-IOC.388}

Background High match frequency in professional men's football has been associated with injury risk. It is unclear how this is affected by the activities of club support staff.

Objective To determine whether the structures and processes adopted by a performance and healthcare team (PHCT) were associated with player availability (PA) during periods of match congestion, using the Integrated Team Effectiveness Model.

Design Sequential explanatory mixed method case study. Setting A single English Championship football club.

Participants Ten PHCT staff from medical, sport science, and data analysis departments.

Interventions The PHCT completed validated team process/ structure questionnaires twice monthly during the 2017-18 season. PA and match frequency data were provided by the PHCT, who also participated in a post-season focus group.

Main Outcome Measures Associations between PA, match congestion (i.e. $\leq 3$ days between matches) and team structures/ 